\title{
International Association of Maritime Universities (IAMU) Section of the WMU Journal of Maritime Affairs
}

\author{
Glenn Blackwood
}

Published online: 25 March 2014

(C) World Maritime University 2014

The International Association of Maritime Universities (IAMU) is pleased to announce that an agreement was recently reached with the World Maritime University (WMU) for the inclusion of an IAMU Section in the WMU Journal of Maritime Affairs (JoMA). WMU is a foundation member of IAMU, and I sincerely thank them for making this initiative possible. This initiative is particularly welcome as it provides a great opportunity not only to publish high-quality reviewed articles based on research but also to have the articles indexed in Scopus, Google Scholar, etc.

IAMU was founded in November 1999 by seven universities with a shared recognition of the significance of maritime education and training in the globalised international shipping arena. At the time of writing, IAMU has a membership of 57 institutions from the world's maritime education and training universities/academies/faculties, and its work is supported by The Nippon Foundation.

All IAMU members recognise the significance of maritime education and training and note that the shipping industry is an essential global service, in which human resources are the critical elements. It is only feasible to secure, and to preserve highly qualified human resources in the maritime industries through effective education and training which derives from scientific and academic rigour, developing clear links between practical skills and management techniques, and we must all maintain a focus on quality.

Each year IAMU supports a small number of research projects, and publishes academic papers presented at the Annual General Assembly. The opportunity for members to also publish their work in a dedicated IAMU Section of the WMU Journal of Maritime Affairs is viewed as further enhancing the aims of IAMU. The IAMU Section will follow JoMA current policy and contain peer-reviewed articles, peer-reviewed issues of contemporary interest, reports and comments, and book reviews.

\footnotetext{
G. Blackwood $(\bowtie)$

International Association of Maritime Universities, 3-4-10, Toranomon, Minato-ku, Tokyo 105-0001, Japan

e-mail: j-info@iamu-edu.org

G. Blackwood

Fisheries and Marine Institute of Memorial University of Newfoundland, St John's, NL, Canada
} 
The focus of the new IAMU Section will be maritime education and training (MET). In this context, MET is considered to include a wide range of issues associated with all forms of education and training which are related to maritime activities carried out by persons both at sea and onshore. This could include, but not be limited to the following:

- Systems of maritime education and training, e.g. international, national, and higher education and vocational training;

- Impacts on maritime education and training, e.g. international conventions, maritime industry needs, government regulation;

- Curriculum development, e.g. processes, review, innovations, balancing conflicting requirements and objectives;

- Course delivery, e.g. classroom-based learning, competency-based training, elearning, flexible learning, blended learning;

- Teaching practise, e.g. teacher-centred, student-centred, education and training technologies, multi-cultural students, teaching exemplars;

- Assessment, e.g. linking objectives and assessment, methods, evaluation of results, assessment exemplars;

- Quality, e.g. standards, measuring outcomes and effectiveness, teacher training, teaching competence; and

- Issues impacting MET, e.g. lifelong learning, changing educational environment, attractiveness of the teaching profession and recruitment.

The success of the IAMU Section very much depends on the membership of IAMU (i.e. the member institutions and their staff, the International Executive Board (IEB), and the Secretary's Office) working to support this important initiative.

Because of the importance of this initiative, the IEB invited the highly experienced and respected Professor Barrie Lewarn to take on the role of IAMU Section editor for the next 3 years. He will be supported in this role by the IAMU Secretary's Office. Professor Lewarn's main tasks will be to work closely with the WMU editors to develop the IAMU Section to enhance the Journal of Maritime Affairs, manage the peer review process for the IAMU Section of the journal, review with the WMU editors the annual progress of the development of the IAMU Section, and report on progress to the IEB.

Our target is to have one or two articles processed in time for the October 2014 edition of the JoMA. However, because of publication deadlines, this very much depends on members submitting articles as soon as possible.

The IAMU Annual General Assembly has consistently produced some high-quality papers; however, members are encouraged to take a further step and become actively involved and support this exciting initiative to ensure its success. 